\title{
Antimicrobial resistance profiles and oxacillinase genes in carbapenem-resistant Acinetobacter baumannii isolated from hospitalized patients in Santa Catarina, Brazil
}

\author{
Giselle Dall Cortivo ${ }^{[1]}$, Andréia Gutberlet ${ }^{[2]}$, Jéssica Augustini Ferreira ${ }^{[2]}$, \\ Leslie Ecker Ferreira ${ }^{[2],[3]}$, Roseneide Campos Deglmann ${ }^{[2],[3],}$ \\ Glauco Adrieno Westphal ${ }^{[3]}$ and Paulo Henrique Condeixa de França ${ }^{[2],[3]}$
}

\begin{abstract}
[1]. Laboratório de Microbiologia Clínica, Hospital Regional Hans Dieter Schmidt, Joinville, Santa Catarina, Brasil. [2]. Departamento de Farmácia, Universidade da Região de Joinville - UNIVILLE, Joinville, Santa Catarina, Brasil. [3]. Departamento de Medicina, Universidade da Região de Joinville - UNIVILLE, Joinville, Santa Catarina, Brasil.
\end{abstract}

\begin{abstract}
Introduction: Carbapenems are the therapy of choice for treating severe infections caused by the Acinetobacter calcoaceticusAcinetobacter baumannii complex. We aimed to assess the prevalence and antimicrobial susceptibility profiles of producers of distinct oxacillinases among nosocomial isolates of the A. calcoaceticus-A. baumannii complex in a 249-bed general hospital located in Joinville, Southern Brazil. Methods: Of the 139 A. baumannii clinical isolates with reduced susceptibility to carbapenems between 2010 and 2013, 118 isolates from varying anatomical sites and hospital sectors were selected for genotypic analysis. Five families of genes encoding oxacillinases, namely $b l a_{\text {OXA-23-like, }}, b l a_{\text {OXA-24-like }}, b l a_{\text {OXA-51-like }}, b l a_{\text {OXA-58-like }}$, and $b l a_{\text {OXA-143-like, }}$, were investigated by multiplex polymerase chain reaction (PCR). Results: Most $(87.3 \%)$ isolates simultaneously carried the $b l a_{\text {OXA-23-like }}$ and $b l a_{\text {OXA-51-like }}$ genes, whereas three $(2.5 \%)$ isolates harbored only bla $a_{\text {OXA-51-like }}$ ones. The circulation of carbapenemresistant isolates increased during the study period: from none in 2010, to 22 in 2011, 64 in 2012, and 53 in 2013. Conclusions: Isolates carrying the $b l a_{\text {OXA-23-like }}$ and $b l a_{\text {OXA-51-like }}$ genes were widely distributed in the hospital investigated. Because of the worsening scenario, the implementation of preventive measures and effective barriers is needed.
\end{abstract}

Keywords: Carbapenem resistance. Acinetobacter. Nosocomial infection. Oxacillinases.

\section{INTRODUCTION}

In the last decade, the Acinetobacter calcoaceticusAcinetobacter baumannii complex emerged as a major nosocomial pathogen complex worldwide because of its remarkable ability to develop resistance to broad-spectrum antimicrobial agents ${ }^{(1)(2)}$. These bacterial strains can persist for long periods on both wet and dry surfaces, as they have minimal nutritional requirements, are tolerant to various physical conditions such as humidity and temperature, and can cause frequent hospital-acquired infection outbreaks ${ }^{(3)}$. In addition, this complex is highly predominant in intensive care units (ICUs) and has been mainly involved in respiratory tract infections that are associated with mechanical ventilation, postoperative bacteremia, secondary meningitis, and urinary tract infections ${ }^{(1)(2)(4)}$.

Corresponding author: Dr. Paulo Henrique Condeixa de França. Laboratório de Biologia Molecular/Departamento de Medicina/UNIVILLE. Rua Paulo Malschitzki 10, Campus Universitário, Zona Industrial, 89219-710 Joinville, Santa Catarina, Brasil.

Phone: 5547 3461-9197; Fax: 5547 3473-0131

e-mail: ph.franca@univille.br

Received 10 July 2015

Accepted 27 August 2015
Acinetobacter baumannii has innate resistance to most antimicrobials commonly used in medical practice, including carbapenems, a class of $\beta$-lactam antibiotics ${ }^{(5)}$. Resistance to carbapenems involves combined mechanisms including enzymatic hydrolysis by $\beta$-lactamases, altered permeability of the outer cell membrane, antibiotic affinity to penicillinbinding proteins, and increased activity of efflux pumps ${ }^{(3)}$. The oxacillinase OXA-type carbapenemases (oxacillinases) belong to the Ambler class D $\beta$-lactamases and constitute the main resistance mechanism to carbapenems worldwide. In the genus Acinetobacter, oxacillinases are genetically divided into six commonly identified subgroups: bla $a_{\text {OXA-23-like }}$ (OXA-23, OXA27, and OXA-49), bla $a_{\text {OXA-24-like }}$ (OXA-24, OXA-25, OXA-26, OXA-40, and OXA-72), bla $a_{\text {OXA-58-like }}, b^{\prime} a_{\text {OXA-14-like }}$ (OXA-143, OXA-231, and OXA-253), bla $a_{\text {OXA-235- }}$, and $b l a_{\text {OXA-51-like }}$, the latter being intrinsic to $A$. baumannii $i^{(6)(7)(8)}$.

Tracking of nosocomial infections, particularly when combined with assessment of phenotypic and genotypic profiles of the most important multidrug-resistant pathogens, enables the implementation of containment measures during infection outbreaks and the development of adequate infection control practices $^{(4)}$. Therefore, the present study aimed to assess the antimicrobial susceptibility profile and the prevalence of producers of distinct oxacillinases among nosocomial isolates in the A. calcoaceticus-A. baumannii complex. 


\section{METHODS}

\section{Clinical isolates}

The study was performed in a general public hospital located in Joinville, Southern Brazil, with 249 beds, 20 of which were located in the ICU. Data on the antimicrobial susceptibility profiles of the A. calcoaceticus-A. baumannii complex and Pseudomonas spp. were obtained from the Hospital Infection Control Service between 2010 and 2013 (n=139). A set of 118 clinical isolates of carbapenem-resistant Acinetobacter baumannii (CRAb) from patients hospitalized for at least $72 \mathrm{~h}^{(9)}$ between June 2011 and August 2013 were used for phenotypic and genotypic assessment. The isolates were obtained from samples of bronchoalveolar lavage fluid, blood, urine, pericardial and abdominal fluids, and catheter tips. Microbial identification was performed exclusively on isolated colonies using the semi-automated system AutoScan ${ }^{\circledR}-4$ (Siemens, Munich, Germany), and was complemented by Gram staining. The study was reviewed and approved by the Research Ethics Committee of University of Region of Joinville (UNIVILLE) (protocol 73464).

\section{Antimicrobial susceptibility analysis}

Antimicrobial susceptibility was assessed via disk diffusion according to the guidelines of the Clinical and Laboratory Standards Institute (CLSI) ${ }^{(10)}$ The antimicrobial agents tested were imipenem $(10 \mu \mathrm{g})$, meropenem $(10 \mu \mathrm{g})$, polymyxin B (300U), tigecycline $(15 \mu \mathrm{g})$, ampicillin/ sulbactam $(10 \mu \mathrm{g} / 10 \mu \mathrm{g})$, amikacin $(30 \mu \mathrm{g})$, gentamicin $(10 \mu \mathrm{g})$, ciprofloxacin $(5 \mu \mathrm{g})$, ceftriaxone $(30 \mu \mathrm{g})$, cefepime $(30 \mu \mathrm{g})$, piperacillin/tazobactam $(100 \mu \mathrm{g} / 10 \mu \mathrm{g})$, and sulfamethoxazole/ trimethoprim $(1.25 \mu \mathrm{g} / 23.75 \mu \mathrm{g})$, all of which were purchased from Oxoid (Cambridge, England). The minimum inhibitory concentrations (MICs) for imipenem, meropenem, polymyxin $\mathrm{B}$, and tigecycline were determined using Etest ${ }^{\mathbb{}}$ strips according to the manufacturer's instructions (bioMérieux, Marcy-l'Etoile, France).

The sizes of the inhibition zones formed in the presence of the antimicrobials were interpreted as recommended by the $\mathrm{CLSI}^{(10)}$, except for tigecycline, for which there is no standard until date $^{(11)}$. In the latter case, the interpretation criteria used were those adopted by the United States Food and Drug Administration for enterobacteria when using the disk diffusion method, namely susceptible: $\geq 19 \mathrm{~mm}$, intermediate: $15-18 \mathrm{~mm}$, and resistant: $\leq 14 \mathrm{~mm}(9)$.

\section{Phenotypic assessment of carbapenemase- producing isolates}

Isolates with inhibition zones of $\leq 13 \mathrm{~mm}$ in the disk diffusion test and a MIC $\geq 16 \mu \mathrm{g} / \mathrm{mL}$ in the Etest ${ }^{\circledR}$ were considered possible producers of carbapenemases and potentially resistant to both imipenem and meropenem. The modified Hodge test was not used in this study because the CLSI no longer recommends it for use in routine laboratory screening for carbapenemaseproducing strains ${ }^{(10)}$.

\section{Detection of genes encoding oxacillinases}

Bacterial deoxyribonucleic acid (DNA) was extracted by heat shock ${ }^{(12)}$. Two to three medium-sized colonies of each isolate were suspended in $150 \mu \mathrm{L}$ of sterile ultrapure water (MilliQ, São Paulo, Brazil). The suspensions were heated in a boiling water bath for $5 \mathrm{~min}$, followed by cooling in an ice bath for $5 \mathrm{~min}$. The boiling and cooling procedures were repeated once more, followed by centrifugation at $8,000 \times g$ for $10 \mathrm{~min}$. The supernatants containing the DNA were collected and the absorbance at 260 and $280 \mathrm{~nm}$ was determined by spectrophotometry. An aliquot of each supernatant $(100 \mu \mathrm{L})$ was stored at $-20^{\circ} \mathrm{C}$.

To confirm the identity of the clinical A. baumannii isolates to species level, the extracted DNA was used for PCR amplification of a single 722-bp segment of the citrate synthase gene $(g l t A)$ using the specific primer pair gltA-F (5'-AATTTACAGTGGCACATTAGGTCC-3') and gltA-R (5'-GCAGAGATACCAGCAGAGATACACG-3'). PCR reactions were performed in an XP Cycler device (BIOER Technology, Tokyo, Japan) using the following program: initial denaturation at $94^{\circ} \mathrm{C}$ for $3 \mathrm{~min}, 30$ cycles at $94^{\circ} \mathrm{C}$ for $1 \mathrm{~min}$, $62^{\circ} \mathrm{C}$ for $30 \mathrm{~s}$, and $72^{\circ} \mathrm{C}$ for $1 \mathrm{~min}$, and a final extension at $72^{\circ} \mathrm{C}$ for $10 \min ^{(13)}$.

Multiplex PCR was used to identify five families of oxacillinase-encoding genes, namely $b l a_{\text {OXA-23-like }}, b l a_{\text {OXA-24 }}$-like, $b l a_{\text {OXA-51-like, }}, b l a_{\text {OXA-58-like }}$, and $b l a_{\text {OXA-143-like, }}$, using the gene-specific primer pairs listed in Table $\mathbf{1}^{(14)(15)}$.

For this purpose, PCR reactions were performed in a final volume of $50 \mu \mathrm{L}$ containing 50 to $500 \mathrm{ng}$ of extracted DNA, $1 \mathrm{U}$ Platinum ${ }^{\circledR}$ Taq DNA Polymerase (Invitrogen, São Paulo, Brazil), $0.2 \mathrm{mM}$ dNTPs (GE Healthcare, Little Chalfont, UK), $1 \times$ PCR Buffer (Invitrogen), $1.5 \mathrm{mM} \mathrm{MgCl}$ (Invitrogen), and $20 \mathrm{pmol}$ of each primer (Invitrogen). The thermal cycling program was adapted from Woodford et al..$^{(13)}$ and consisted of denaturation at $94^{\circ} \mathrm{C}$ for $3 \mathrm{~min}$ followed by 30 cycles at $94^{\circ} \mathrm{C}$ for $1 \mathrm{~min}$, $52^{\circ} \mathrm{C}$ for $30 \mathrm{~s}$, and $72^{\circ} \mathrm{C}$ for $1 \mathrm{~min}$, and a final extension at $72^{\circ} \mathrm{C}$ for $10 \mathrm{~min}$.

The PCR products were subjected to $1 \%$ agarose gel electrophoresis, and their size was confirmed under ultraviolet (UV) light (MiniBis-Pro Photodocumentation System; DNR Bio-Image Systems Ltd., Jerusalem, Israel), followed by image scanning.

The following standard oxacillinase-producing $A$. baumannii strains from the culture collection of the Oswaldo Cruz Foundation [Fundação Oswaldo Cruz (FIOCRUZ/RJ)] were used as positive controls: strain $7892\left(b l a_{\text {OXA-24-like }}\right)$, strain $7740\left(b l a_{\text {OXA-58-like }}\right)$, and strain $7572\left(b_{\text {OXA-23-like }}\right.$ and $\left.b l a_{\text {OXA-143-like }}\right)$.

\section{RESULTS}

The 118 clinical isolates of $A$. baumannii obtained during routine diagnostic assessment of patients with suspected infection were collected primarily from bronchoalveolar lavage fluid $(n=64)$ and blood $(n=27)$, accounting for $77.1 \%$ of the isolates, and less frequently from wound secretions $(n=10)$, 
TABLE 1 - Primer pairs used for the detection of oxacillinase-encoding genes.

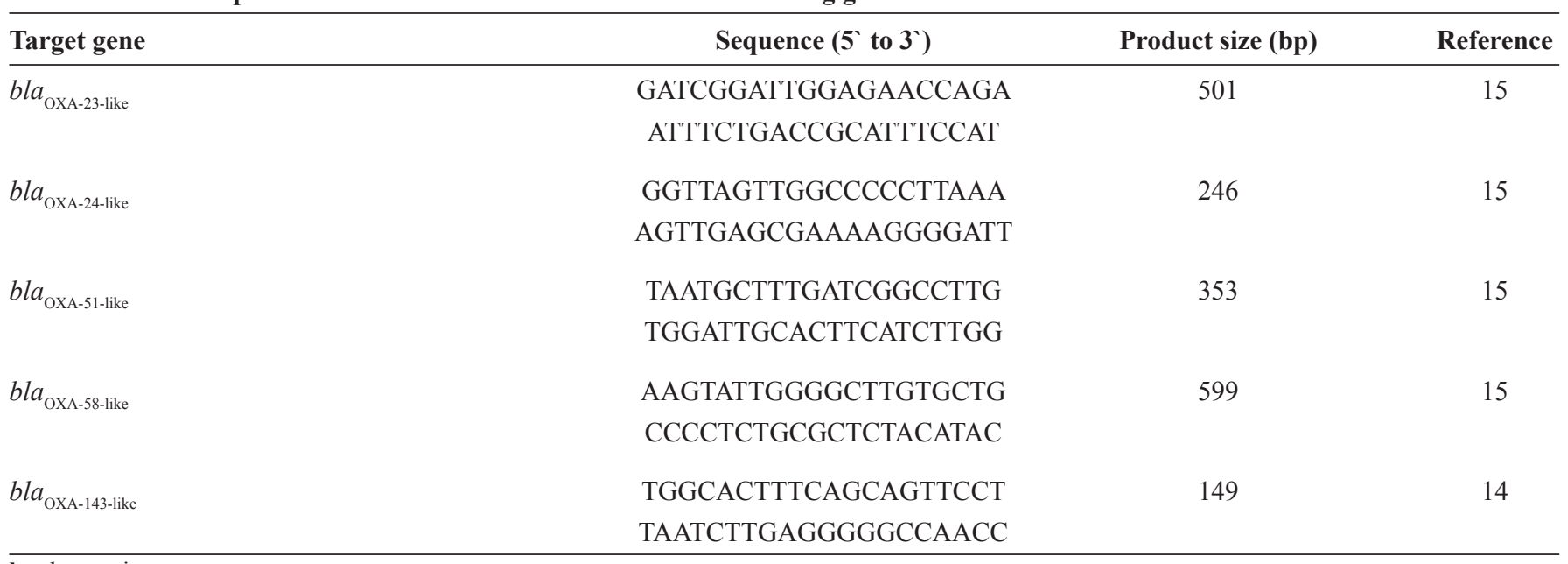

bp: base pair.

urine $(n=8)$, other bodily fluids $(n=5)$, sputum $(n=2)$, and catheter tips $(n=2)$. Most $(62.7 \% ; n=74)$ isolates were obtained from patients hospitalized in the ICU, and the remaining isolates $(n=44)$ came from patients housed in other hospital sectors.

\section{Phenotypic assessment}

All 118 isolates were resistant to the antimicrobials cefepime, ceftriaxone, ciprofloxacin, imipenem, meropenem, and piperacillin/tazobactam (Figure 1). Resistance to amikacin and gentamicin was confirmed in $80.5 \%(n=95)$ and $83.9 \%$ $(n=99)$ of the isolates, respectively. For ampicillin/sulbactam, $94.1 \%(\mathrm{n}=111)$ of the isolates exhibited complete resistance and $5.9 \%(n=7)$ exhibited intermediate resistance. A single $(0.8 \%)$ isolate was susceptible to sulfamethoxazole/trimethoprim. In addition, all isolates tested were susceptible to polymyxin B, whereas $88.1 \%(n=104)$ and $11.9 \%(n=14)$ exhibited complete and intermediate susceptibility to tigecycline, respectively.

The Etest ${ }^{\circledR}$ results revealed that all isolates exhibited minimum inhibitory concentrations (MICs) $\geq 16 \mu \mathrm{g} / \mathrm{mL}$ (resistant phenotype) for imipenem and meropenem, whereas the MICs for polymyxin B and tigecycline ranged from $0.2-2.0 \mu \mathrm{g} / \mathrm{mL}$ and $0.5-4.0 \mu \mathrm{g} / \mathrm{mL}$, respectively.

\section{Genotypic assessment}

Most ( $\mathrm{n}=103 ; 87.3 \%$ ) isolates simultaneously carried the $b l a_{\text {OXA-23-like }}$ and bla $a_{\text {OXA-51-like }}$ genes, whereas three (2.5\%) isolates only harbored the $b l a_{\text {OXA-51-like }}$ gene. Genotyping results were inconclusive for twelve $(10.2 \%)$ isolates. The isolates in which both the $b l a_{\text {OXA-23-like }}$ and $b l a_{\text {OXA-51-like }}$ genes were detected and those harboring only the bla $a_{\text {OXA-51-like }}$ gene had MICs $\geq 16 \mu \mathrm{g} /$ $\mathrm{mL}$ for imipenem and meropenem. The isolates that exhibited either intermediate or complete susceptibility to tigecycline all carried both the $b l a_{\text {OXA-23-like }}$ and $b l a_{\text {OXA-51-like }}$ genes. From the 103 clinical isolates that simultaneously harbored the $b l a_{\text {OXA-23-like }}$ and bla $a_{\text {OXA-51-like }}$ genes, $62(60.2 \%)$ were isolated from the ICU, and the remaining isolates $(\mathrm{n}=41)$ originated from other hospital wards.

\section{Evolution of the antimicrobial susceptibility profile}

In 2010, nine $A$. calcoaceticus- $A$. baumannii complex isolates were identified, from which a single isolate exhibited intermediate susceptibility to the carbapenems imipenem and meropenem. In 2011, 22 carbapenem-resistant Acinetobacter baumannii (CRAb) isolates were identified, representing 84.6\% of the samples. In June of that year, the first nosocomial outbreak of $A$. baumannii was reported; six isolates were confirmed CRAb, four of which were derived from bronchoalveolar lavages of ICU patients. In December 2011, a second outbreak was confirmed, during which five CRAb isolates were identified, three of which were from bronchoalveolar lavages of ICU patients. Notably, up until 2011, all isolates had remained susceptible to tigecycline. Moreover, all CRAb isolates associated with the outbreaks in $2011(\mathrm{n}=11)$ had both the $b l a_{\text {OXA-51-like }}$ and $b l a_{\text {OXA-23-like }}$ genes, were susceptible to tigecycline and polymyxin B, and did not show any differences in the characteristics evaluated when compared with the other isolates.

In 2012, the number of carbapenem-resistant isolates increased to 64 (96.9\%), 40 of which originated from the ICU; 34 of these were collected from bronchoalveolar lavage fluids. In the next year, 53 isolates were confirmed to be resistant, 36 of which were obtained from the ICU, 26 of which were collected from bronchoalveolar lavage fluids. Further, in 2013, eight $(15.1 \%)$ and three $(5.7 \%)$ isolates exhibited intermediate and complete resistance to tigecycline, respectively. Figure 2 shows the evolution of the susceptibility to imipenem, meropenem, and tigecycline.

Figure 3 shows the evolution of the incidence of CRAb isolates between 2011 and 2013 as compared with Pseudomonas spp. from the same hospital that are usually associated with nosocomial infections and are resistant to carbapenems. 


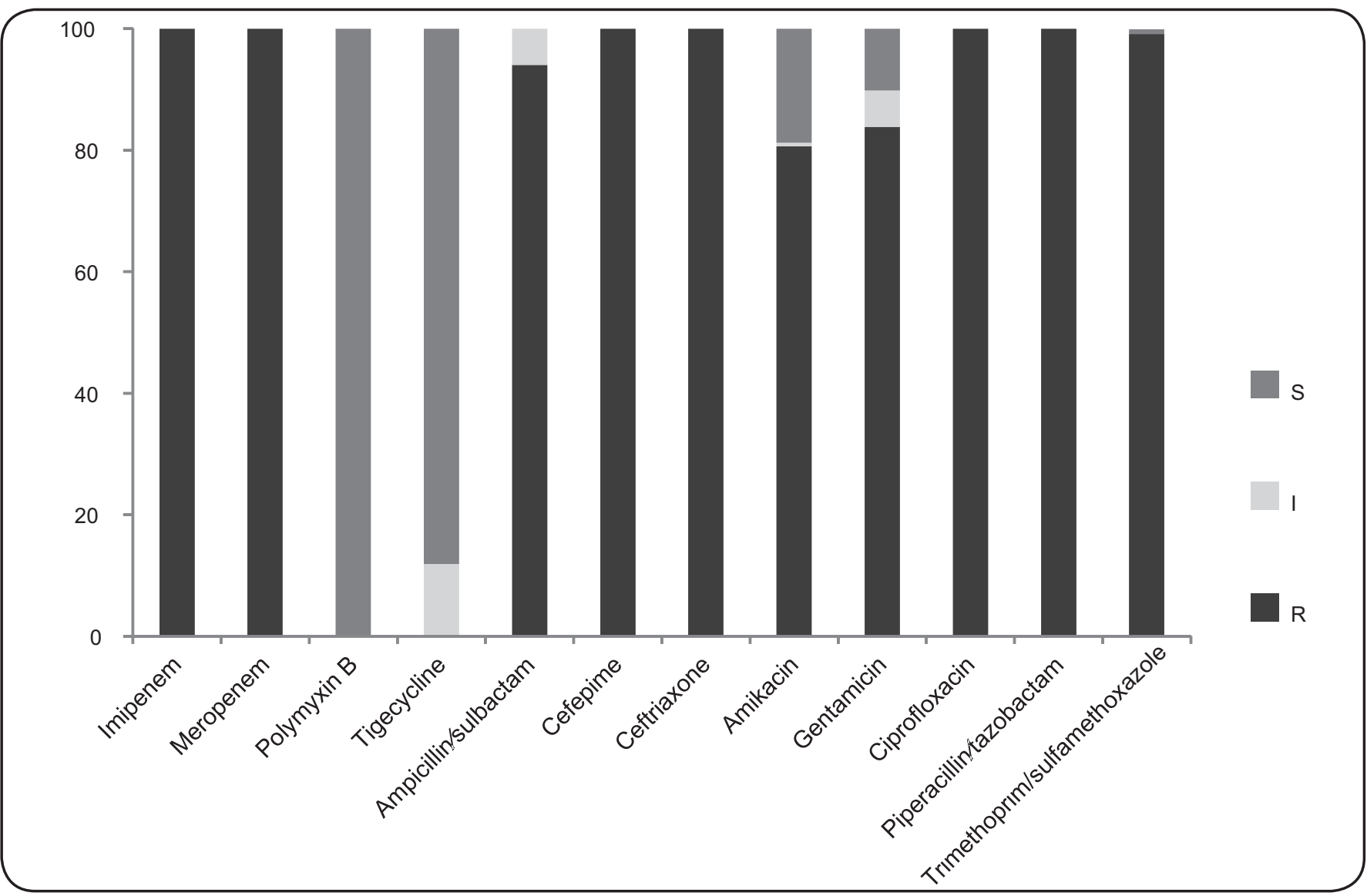

FIGURE 1 - In vitro antimicrobial susceptibility profiles for clinical isolates of the Acinetobacter calcoaceticus-Acinetobacter baumannii complex. S: susceptible; I: intermediate; R: resistant.

\section{DISCUSSION}

Our results revealed that the $b l a_{\text {OXA-23-like }}$ and $b l a_{\text {OXA-51-like }}$ genes were widely distributed in the clinical isolates analyzed, which might have contributed to the increasing incidence of $\mathrm{CRAb}$ strains in the hospital investigated. The predominance of the genotypic profile $b l a_{\text {OXA-23-like }} / b l a_{\text {OXA-51-like }}$ among the clinical isolates investigated led us to hypothesize the occurrence of cross infection.

The A. calcoaceticus-A. baumannii complex has been responsible for nosocomial infection outbreaks in Europe since 1980, mainly in England, France, Germany, Italy, Spain, and the Netherlands ${ }^{(16)}$. In Brazilian hospitals, infections have been reported since 1996, mainly at ICUs ${ }^{(17)}$. Carbapenems became the primary therapeutic options in various hospitals, but the continued use of these antimicrobials has been compromised by the emergence of novel resistance mechanisms ${ }^{(1)}$. The production of oxacillinase enzymes, mainly through the expression of the $b l a_{\text {OXA-23-like }}$ gene, is the most common resistance mechanism reported in CRAb isolates in diverse countries including Bulgaria, China, Iraq, Afghanistan, and French Polynesia ${ }^{(18)}$.

Previous studies conducted in Brazil revealed an increasing incidence of nosocomial outbreaks caused by multi-drug resistant (MDR) strains of the genus Acinetobacter ${ }^{(19)(20)}$. In a study performed from January 2006 to September 2007 in eight hospitals in Rio de Janeiro, 110 imipenem-resistant A. baumannii strains were isolated, among which $87.3 \%$ were producers of OXA-23 carbapenemase ${ }^{(19)}$. Another Brazilian study analyzed the genotypic characteristics of 46 CRAb isolates from eight hospitals in the State of Paraná and reported that all isolates harbored the $b l a_{\text {oxa-23-like }}$ gene $^{(20)}$.

Other studies have revealed that $A$. baumannii strains typically spread through clonal dissemination. A study conducted in Australia in a single hospital during a 10-year period showed that the $b l a_{\text {OXA-23-like }}$ gene, present in most isolates, was responsible for carbapenem resistance. In addition, the clonal relationship among the isolates was evaluated through pulsed-field gel electrophoresis, which demonstrated that the antimicrobial susceptibility profile does not predict isolate clonality $^{(21)}$.

Despite the identification of New Delhi metallo- $\beta$-lactamase 1 (NDM-1)-producing A. baumannii in Londrina in the state of Paraná, the major mechanism of carbapenem resistance in Brazil is through the expression of the bla ${ }_{\text {OXA-23-like }}$ gene ${ }^{(22)(23)}$. In addition, this gene is frequently detected in isolates from Asia and Europe ${ }^{(24)}$, and in most cases, it is found concomitantly with the $b l a_{\text {OXA-51-like }}$ gene ${ }^{(2)(14)}$. Notably, the $b l a_{\text {OXA-23-like }}$ and $b l a_{\text {OXA-51-like }}$ 


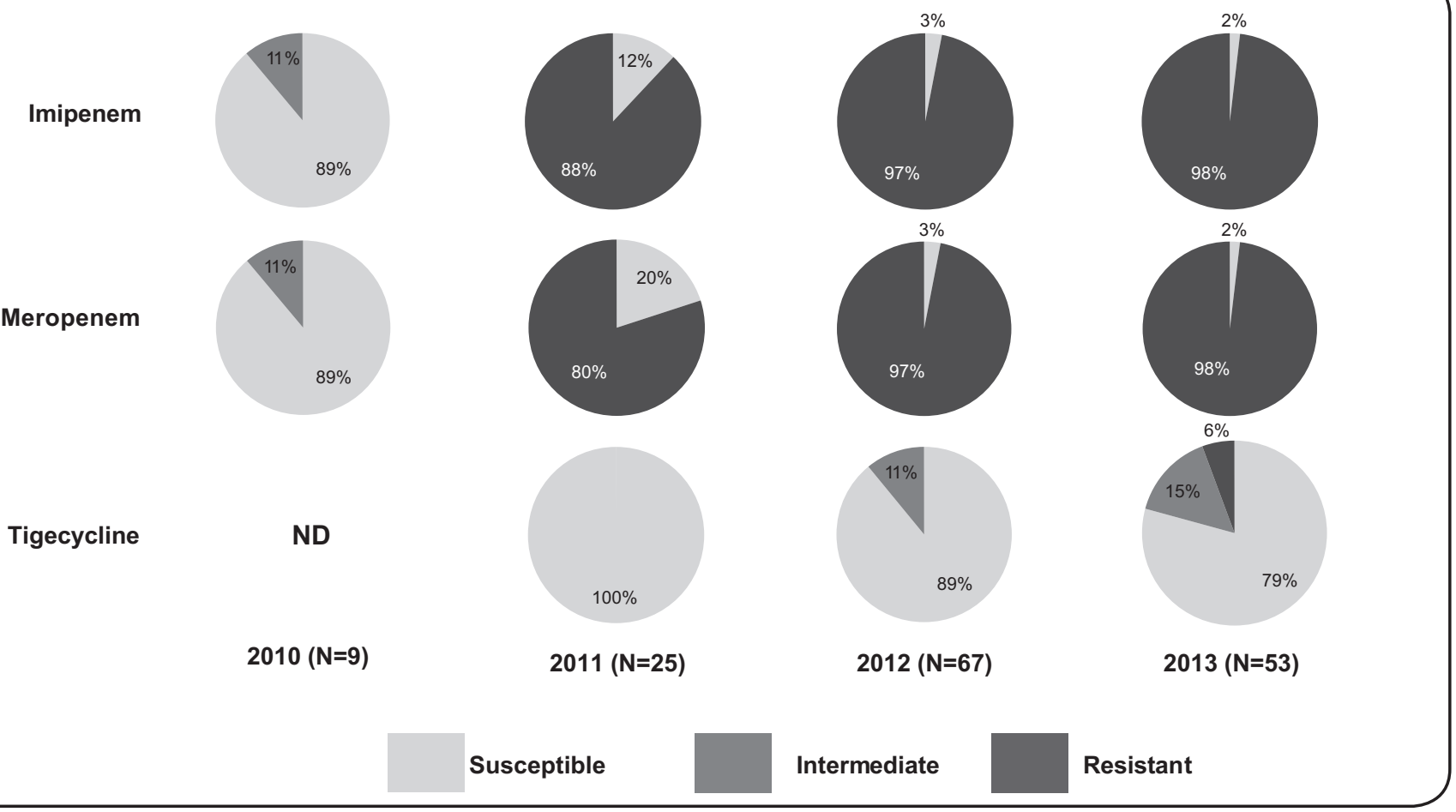

FIGURE 2 - Susceptibility profiles of isolates of the Acinetobacter calcoaceticus-Acinetobacter baumannii complex to the antimicrobials imipenem, meropenem, and tigecycline between 2010 and 2013. ND: not done.

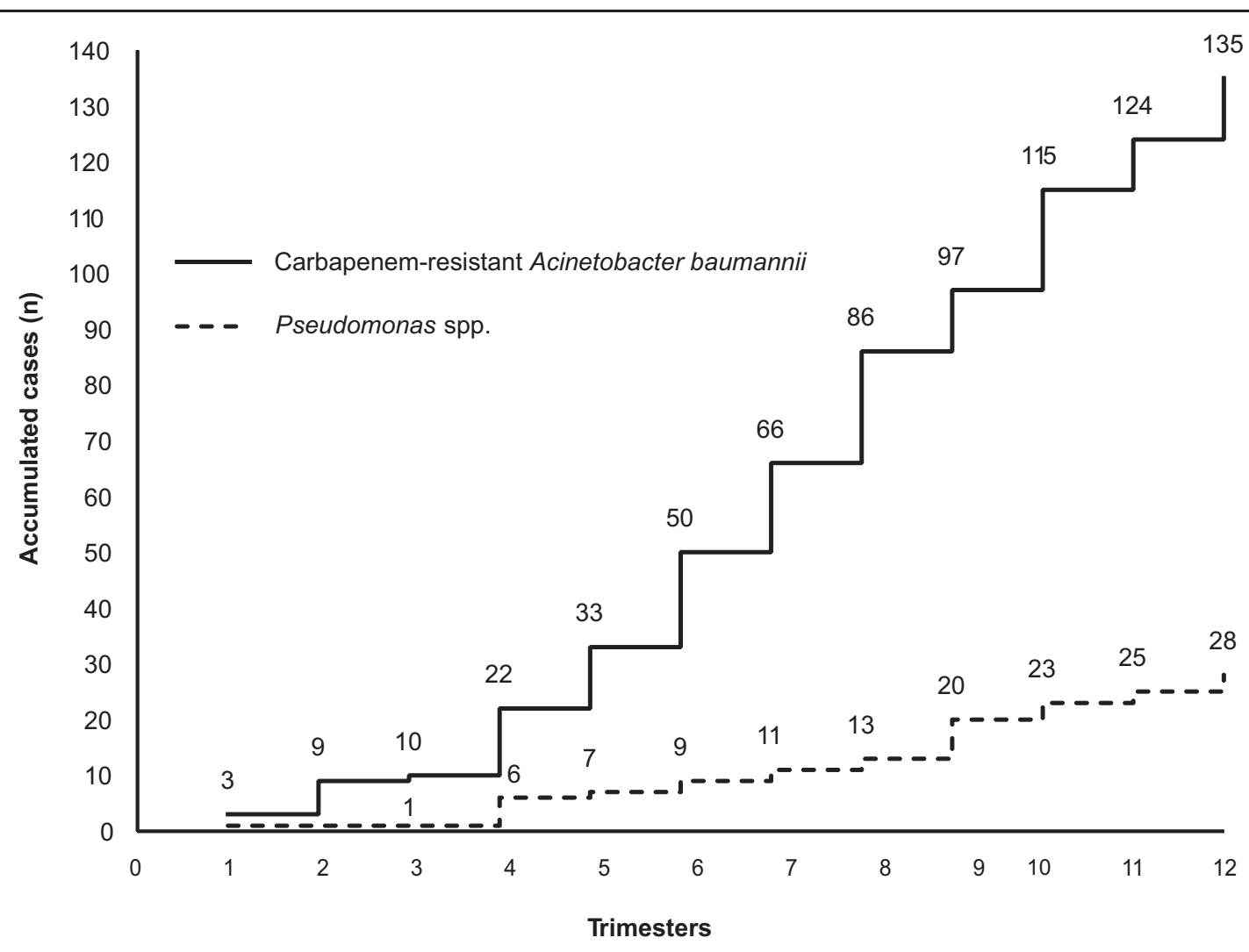

FIGURE 3 - Comparative incidence of carbapenem-resistant Acinetobacter baumannii and carbapenem-resistant Pseudomonas spp. isolates. 
genes may be overexpressed when associated with the insertion sequence ISAbal because this sequence constitutes a promoter region for both genes ${ }^{(25)}$. In the present study, the resistance of the CRAb isolates $(n=6)$ that did not contain any of the $b l a_{\mathrm{OXA}}$ genes investigated may be associated with other, less frequent resistance mechanisms such as altered outer membrane permeability and increased activity of efflux pumps ${ }^{(5)}$.

Many institutions have observed an increased incidence of healthcare-associated infections by $A$. baumannii. This pathogen has become resistant to all $\beta$-lactam antibiotics (including carbapenems), all fluoroquinolones, sulfamethoxazole/ trimethoprim, and most, if not all, aminoglycosides ${ }^{(26)}$. Therefore, treatment options are limited. Tigecycline, colistin, and polymyxin $\mathrm{B}$ can be used as last-resort drugs for the treatment of infections caused by CRAb isolates in hospital settings. However, these antimicrobials have their own limitations and may not be indicated for several clinical conditions. For example, polymyxin $\mathrm{B}$ has nephrotoxic and neurotoxic effects ${ }^{(2)}$. In addition, decreased susceptibility to these antimicrobials became a major concern. A study performed in Spain revealed that the susceptibility to tigecycline decreased during the course of treatment, with an increase in the MIC to $\geq 2 \mu \mathrm{g} / \mathrm{mL}^{(27)}$. In our study, all isolates were susceptible to polymyxin B during the period investigated; however, $10.4 \%$ and $15.1 \%$ of the isolates had intermediate resistance to tigecycline in 2012 and 2013, respectively. Even worse, three (5.7\%) isolates were resistant to tigecycline in the last year of data collection.

The overuse of antimicrobials and the neglect of standard routines for hand hygiene have led to the emergence and spread of MDR pathogens in hospital settings, and the adoption of effective measures to prevent nosocomial outbreaks is warranted $^{(4)(28)}$. The antimicrobial susceptibility profiles evaluated during the period considered in our study indicated a fast increase in circulating CRAb strains, especially when compared to data related to carbapenem-resistant Pseudomonas spp. in the same environment. In addition, the identification of an increasing incidence of CRAb strains also showing phenotypic resistance to tigecycline highlights that treatment options are becoming limited. Taken together, our results suggest an extensive dissemination of CRAb isolates in hospital environments and warrant the need for a systematic review of preventive measures and the implementation of effective outbreak control measures.

\section{CONFLICT OF INTEREST}

The authors declare that there is no conflict of interest.

\section{FINANCIAL SUPPORT}

This study was supported by the Research Fund from the University of Region of Joinville [Fundo de Apoio à Pesquisa/ Universidade da Região de Joinville (FAP/UNIVILLE)].

\section{REFERENCES}

1. El-Ageery SM, Abo-Shadi MA, Alghaithy AA, Ahmad MA, Alsharih NH, Alharbi SA. Epidemiological investigation of nosocomial infection with multidrug-resistant Acinetobacter baumannii. Eur Rev Med Pharmacol Sci 2012; 16:1834-1839.

2. Mendes RE, Bell JM, Turnidge JD, Castanheira M, Jones RN. Emergence and widespread dissemination of OXA-23, -24/40 and -58 carbapenemases among Acinetobacter spp. in AsiaPacific nations: report from the SENTRY Surveillance Program. J Antimicrob Chemother 2009; 6:55-59.

3. Sydnor ER, Perl TM. Hospital epidemiology and infection control in acute-care settings. Clin Microbiol Rev 2011; 24:141-173.

4. Chang HC, Chen YC, Lin MC, Liu SF, Chung, YH, Su MC, et al. Mortality risk factors in patients with Acinetobacter baumannii ventilator: associated pneumonia. J Formos Med Assoc 2011; 110:564-571.

5. Al-Johani SM, Akhter J, Balkhy H, El-Saed A, Younan M, Memish Z. Prevalence of antimicrobial resistance among gram-negative isolates in an adult intensive care unit at a tertiary care center in Saudi Arabia. Ann Saudi Med 2010; 30:364-369.

6. Higgins PG, Pérez-Llarena FJ, Zander E, Fernández A, Bou G, Seifert H. OXA-235, a novel class D $\beta$-lactamase involved in resistance to carbapenems in Acinetobacter baumannii. Antimicrob Agents Chemother 2013; 57:2121-2126.

7. Opazo A, Domínguez M, Bello H, Amyes SG, González-Rocha G. OXA-type carbapenemases in Acinetobacter baumannii in South America. J Infect Dev Ctries 2012; 6:311-316.

8. Zander E, Bonnin RA, Seifert H, Higgins PG. Characterization of blaOXA-143 variants in Acinetobacter baumannii and Acinetobacter pittii. Antimicrob Agents Chemother 2014; 58:2704-2708.

9. Garner JS, Jarvis WR, Emori TG, Horan TC, Hughes JM. CDC definitions for nosocomial infections, 1988. Am J Infect Control 1988; 16:128-140.

10. Clinical and Laboratory Standards Institute (CLSI). Performance standards for antimicrobial susceptibility testing: 20th informational supplement. CLSI; 2013. (Accessed 2015 June 4) Available at: http://www.clsi.org/

11. The Medical Letter on Drugs and therapeutics. Tigecycline (Tygacil). Med Lett Drugs Ther 2005; 47:73-74.

12. Vaneechoutte M, Dijkshoorn L, Tjernberg I, Elaichouni A, de-Vos P, Claeys G, et al. Identification of Acinetobacter genomic species by amplified ribossomal DNA restriction analysis. J Clin Microbiol 1995; 33:11-15.

13. Bartual SG, Seifert H, Hippler C, Luzon MA, Wisplinghoff H, Rodríguez-Valera F. Development of a multilocus sequence typing scheme for characterization of clinical isolates of Acinetobacter baumannii. J Clin Microbiol 2005; 43:4382-4390.

14. Higgins PG, Lehmann M, Seifert H. Inclusion of OXA-143 primers in a multiplex polymerase chain reaction (PCR) for genes encoding prevalent OXA carbapenemases in Acinetobacter spp. Int J Antibicrob Agents 2010; 35:305.

15. Woodford N, Ellington MJ, Coelho JM, Turton JF, Ward ME, Brown S, et al. Multiplex PCR for genes encoding prevalent OXA carbapenemases in Acinetobacter spp. Int J Antimicrob Agents 2006; 27:3513.

16. Peleg AY, Seifert H, Paterson DL. Acinetobacter baumanii: emergence of a successful pathogen. Clin Microbiol Rev 2008; 21:538-582.

17. Levin AS, Mendes CM, Sinto SI, Sader HS, Scarpitta CR, Rodrigues E, et al. An outbreak of multiresistant Acinetobacter 
baumannii in a university hospital in São Paulo, Brazil. Infect Control Hosp Epidemiol 1996; 17:366-368.

18. Mugnier PD, Poirel L, Naas T, Nordmann P. Worldwide dissemination of the bla ${ }_{\text {OXA-23 }}$ carbapenemase gene of Acinetobacter baumannii. Emerg Infect Dis 2010; 16:35-40.

19. Carvalho KR, Carvalho-Assef APD, Peirano G, Santos LCG, Pereira MJF, Asensi MD. Dissemination of multidrug-resistant Acinetobacter baumannii genotypes carrying bla $_{\mathrm{OXA}-23}$ collected from hospitals in Rio de Janeiro, Brazil. Int J Antimicrob Agents 2009; 34:25-28.

20. Cieslinski JM, Arend L, Tuon FF, Silva EP, Ekermann RG, DallaCosta LM, et al. Molecular epidemiology characterization of OXA23 carbapenemase-producing Acinetobacter baumannii isolated from 8 Brazilian hospitals using repetitive sequence-based PCR. Diagn Microbiol Infect Dis 2013; 77:337-340.

21. Runnegar N, Sidjabat H, Goh HM, Nimmo GR, Schembri MA, Paterson DL. Molecular epidemiology of multidrug-resistant Acinetobacter baumannii in a single institution over a 10 -year period. J Clin Microbiol 2010; 48:4051-4056.

22. Mostachio AK, Levin AS, Rizek C, Rossi F, Zerbini J, Costa SF. High prevalence of OXA-143 and alteration of outer membrane proteins in carbapenem-resistant Acinetobacter spp. isolates in Brazil. Int J Antimicrob Agents 2012; 39:396-401.
23. Pillonetto M, Arend L, Vespero EC, Pelisson M, Chagas TP, Carvalho-Assef AP, et al. First report of NDM-1-producing Acinetobacter baumannii sequence type 25 in Brazil. Antimicrob Agents Chemother 2014; 58:7592-7594.

24. Fu Y, Zhou J, Zhou H, Yang Q, Wei Z, Yu Y, et al. Wide dissemination of OXA-23 producing carbapenem-resistant Acinetobacter baumannii clonal complex 22 in multiple cities of China. J Antimicrob Chemother 2010; 65:644-650.

25. Ruiz M, Marti S, Fernandez-Cuenca F, Pascual A, Vila J. High prevalence of carbapenem-hydrolysing oxacilinases in epidemiologically related and unrelated Acinetobacter baumannii clinical isolates in Spain. Clin Microbiol Infect 2007; 13:1198.

26. Perez F, Hujer AM, Hujer KM, Decker BK, Rather PN, Bonomo RA. Global challenge of multidrug-resistant Acinetobacter baumannii. Antimicrob Agents Chemother 2007; 51:3471-3484.

27. Hernández-Torres A, García-Vázquez E, Gómez J, Canteras M, Ruiz $\mathrm{J}$, Fernández-Rufete A, et al. Carbapenem and multidrug-resistant Acinetobacter baumannii colonisation/infection: epidemiology and factors associated with infection. Med Clin (Barc) 2010; 135:389-396.

28. Castelo-Branco-Fortaleza CM, Moreira-de-Freitas F, da-Paz-Lauterbach G. Colonization pressure and risk factors for acquisition of imipenemresistant Acinetobacter baumannii in a medical surgical intensive care unit in Brazil. Am J Infect Control 2013; 41:263-265. 